\title{
Denopamine Augments the Left Ventricular Pump Function in Infants with Ventricular Septal Defect and Pulmonary Hypertension: Doppler Echocardiographic Analysis
}

\author{
Hideshi Tomita, Kazuo Ikeda and Shunzo Chiba \\ Department of Pediatrics, School of Medicine, Sapporo \\ Medical University, Sapporo 060
}

\begin{abstract}
Tomita, H., Ineda, K. and Chiba, S. Denopamine Augments the Left Ventricular Pump Function in Infants with Ventricular Septal Defect and Pulmonary Hypertension: Doppler Echocardiographic Analysis. Tohoku J. Exp. Med., 1994, $172(2), 111-121$ The purpose of this study is to evaluate hemodynamic effects and clinical benefit of oral denopamine in infants with left to right shunt disease. We measured heart rates, left ventricular end-diastolic and end-systolic dimensions, shortening fractions, peak and mean flow velocities of the main pulmonary artery and ascending aorta at 30,60 and 90 min after oral denopamine using Doppler echocardiography. Seventeen infants with ventricular septal defect and pulmonary hypertension (mean pulmonary artery pressures higher than 25 $\mathrm{mmHg}$ ) were divided into two groups depending upon the doses of denopamine; group 1 received $1 \mathrm{mg} / \mathrm{kg}$, and group 2 was given $0.5 \mathrm{mg} / \mathrm{kg}$. Serum concentrations of denopamine were measured with high performance liquid chromatography after completion of these evaluations. In both groups, heart rates and left ventricular shortening fractions increased, and left ventricular end-systolic dimensions decreased significantly. Although peak and mean velocities of aortic and pulmonary flows increased significantly, there were no significant alterations in peak and mean velocity ratios of pulmonary to aortic flow. There was no significant difference in the serum concentration of denopamine between the two groups. However, percentage changes of some indices, such as heart rates, left ventricular end-systolic dimensions, peak aortic and pulmonary flow velocities, and mean aortic flow velocities exponentially correlated to serum concentrations of denopamine. In conclusion, denopamine is supposed to have beneficial actions to augment the systemic output by enhancing the left ventricular pump function in patients of ventricular septal defect. However, we should be careful for denopamine not to produce excessive increases in heart rate and pulmonary blood flow. denopamine; ventricular septal defect; pulmonary hypertension; infant
\end{abstract}

Several inotropic agents, such as digitalis and catecholamines, have been used clinically in medical management of infants with congestive heart failure caused

Received October 20, 1993; revision accepted for publication December 27, 1993.

Address for reprints: Hideshi Tomita M.D., Department of Pediatrics, School of Medicine, Sapporo Medical University, South 1, West 16, Chuo-ku, Sapporo 060, Japan. 
by large ventricular septal defect and pulmonary hypertension. However, these agents, which usually have not simply inotropic but some chronotropic and vascular actions, do not always confer beneflcial effects on these patients with large left to right shunt, because an excessive increase in pulmonary blood flow induced by active pulmonary vasodilation sometimes leads to aggravation of lung congestion. Although there are several studies regarding its hemodynamic effects and clinical usefulness in adult patients with failing heart (Kino et al. 1983, 1986), few studies have been carried out on its effectiveness in babies (Ishikawa et al. 1989). Furthermore, there are scanty data on the hemodynamic effects of oral denopamine in infants with congestive heart failure, especially complicated with left to right shunt disease. The purpose of this study is to evaluate hemodynamic alterations caused by oral denopamine in infants with ventricular septal defect and pulmonary hypertension, using Doppler echocardiography.

\section{Methods}

Patients. Infants with ventricular septal defect and pulmonary hypertension, whose mean pulmonary pressure was higher than $25 \mathrm{mmHg}$, were eligible for inclusion in this study. Seventeen patients, one of whom was complicated with atrial septal defect, participated in the protocol after informed consent of their parents was obtained. These infants were divided into two groups depending upon the doses of denopamine. Denopamine of $1.0 \mathrm{mg} / \mathrm{kg} / \mathrm{dose}$ was administered to ten patients in group 1 , and $0.5 \mathrm{mg} / \mathrm{kg} /$ dose to seven infants in group 2. Ranges in age of these groups were from 3 to 9 months (average, 6 months) in group 1, and 2 to 11 months (average, 5 months) in group 2.

Study protocol. All examinations were performed under medications of oral digoxin (8-10 $\mu \mathrm{g} / \mathrm{kg} /$ day), furosemide $(1-2 \mathrm{mg} / \mathrm{kg} /$ day) and spironolactone $(1-2 \mathrm{mg} / \mathrm{kg} /$ day $)$. Patients underwent repeated Doppler echocardiographic studies before and at 30,60 and 90 min after oral denopamine. After completion of these evaluations, serum concentrations of denopamine were measured with high performance liquid chromatography with electrochemical detection (Tagawa et al. 1990) at Research Laboratory, Tanabe Seiyaku Co. (Osaka). Precise baseline hemodynamics were evaluated with cardiac catheterization in a few week of the Doppler echocardiography.

Catheterization assessment. All patients underwent cardiac catheterization to evaluate basic hemodynamics, in 0-30 days (average, 7 days) of echocardiography. Oxygen consumption was derived from LaFarge's standard. Oxygen saturation was measured by an OSM2 Hemoximeter (Radiometer Co., Copenhagen, Denmark). Right and left (through foramen ovale or atrial septal defect) heart pressures were obtained via a fluid-filled catheter system. Cardiac output was measured by the Fick method. Vascular resistance was expressed as Wood units.

Echocardiographic assessment. Each patient underwent M-mode, two dimensional and Doppler echocardiographic examinations using a Toshiba model 160A (Toshiba Co., Tokyo). Echocardiography was performed before and at 30,60,90 min after oral denopamine in a quiet, resting state; intravenous secobarbital sodium $(5 \mathrm{mg} / \mathrm{kg})$ was used for sedation. Those who could not stay quiet for $90 \mathrm{~min}$ by a single injection of secobarbital were excluded from this study. M-mode echo and Doppler flow pattern were recorded on a Line scan recorder-20B (Toshiba Co., Tokyo) by $50 \mathrm{~mm} / \mathrm{sec}$. Heart rates (HR), and left ventricular end-diastolic (LVDd) and end-systolic (LVDs) dimensions were measured, and shortening fractions (SF) were calculated. Pulsed Doppler ascending aortic flow from the parasternal or apical long-axis, and main pulmonary arterial flow from the parasternal short-axis were recorded with sampling both just above the midpoint of the aortic and 


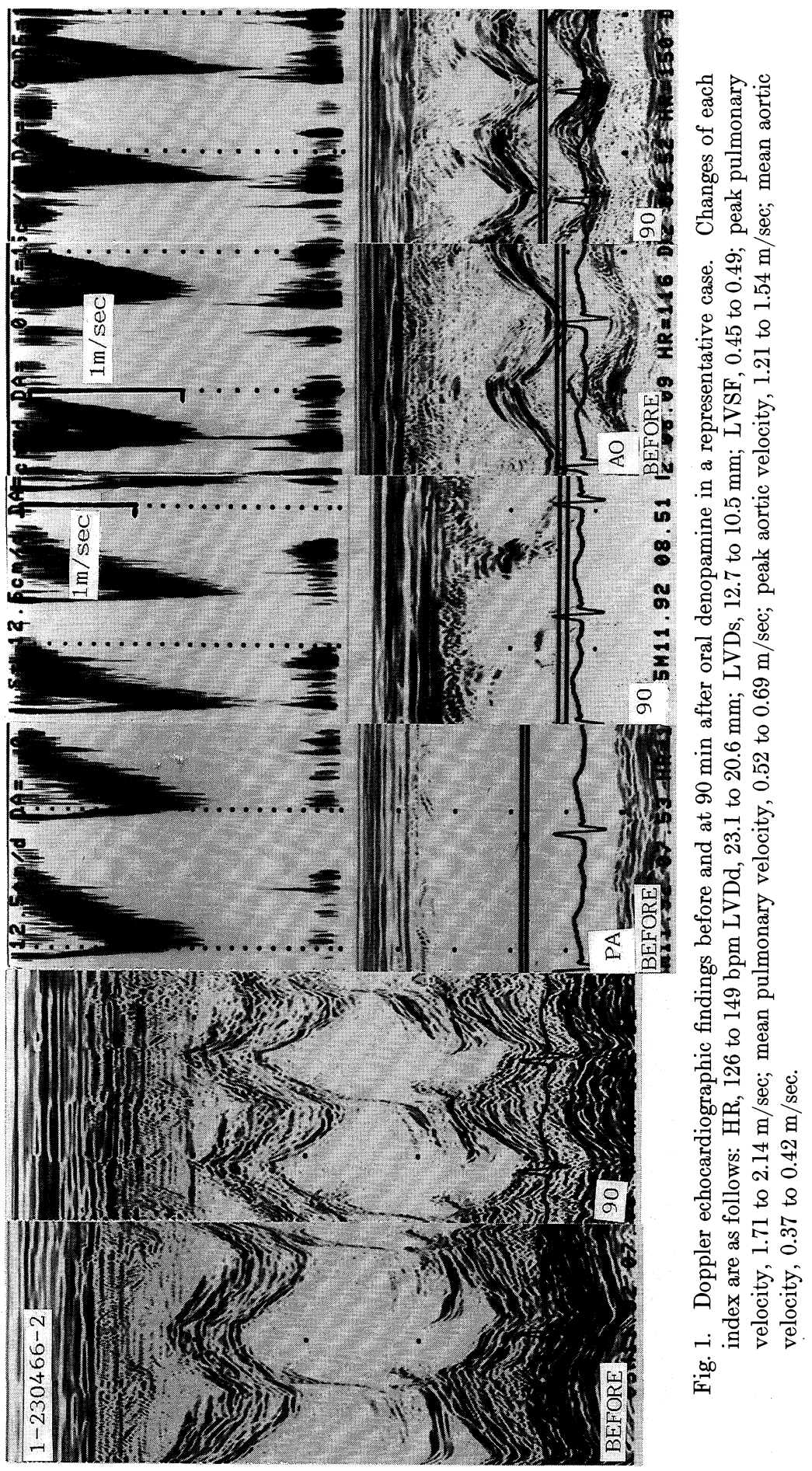


pulmonary leaflets, where the angle between the ultrasound beam and the color flow was very close to $0^{\circ}$ (Fig. 1).

Statistical analysis. Data are expressed as mean value \pm s.e. Statistically significant differences between the two groups were determined by Student's $t$-test, and those among the three groups were resolved by a two-way analysis of variance without replication. Statistical significance was taken as $p<0.05$.

\section{RESUlts}

\section{Basic hemodynamic condition}

At rest, pulmonary to systemic flow ratio, mean pulmonary pressure and pulmonary resistance were comparable in the 2 groups (Table 1 ).

\section{Changes of heart rates}

Heart rates began to increase at $60 \mathrm{~min}$ after denopamine. Eventually, it increased from $136 \pm 3$ to $154 \pm 3 \mathrm{bpm}$ in group 1 , and from $138 \pm 5$ to $153 \pm 9 \mathrm{bpm}$ in group 2, respectively (Fig. 2).

\section{Changes of $L V$ dimensions}

Although LVDd tended to decrease at $90 \mathrm{~min}$ in group 1 (from $27.1 \pm 1.5$ to $25.2 \pm 1.7 \mathrm{~mm}$ ), there was no significant alteration in group 2 (from $24.8 \pm 1.5$ to

TABLE 1. Basic hemodynamic characteristics of patients

\begin{tabular}{cccc}
\hline & Qp/Qs & $\begin{array}{c}\text { Mean PA pressure } \\
(\mathrm{mmHg})\end{array}$ & $\begin{array}{c}\mathrm{Rp} \\
\left(\mathrm{u} \cdot \mathrm{m}^{2}\right)\end{array}$ \\
\hline Group 1 & $0.6-4.2(2.5 \pm 0.3)$ & $32-52(39 \pm 2)$ & $1.6-9.4(4.2 \pm 0.7)$ \\
Group 2 & $0.8-3.9(2.4 \pm 0.4)$ & $32-54(44 \pm 3)$ & $1.2-8.6(4.9 \pm 0.9)$ \\
\hline
\end{tabular}

( ): mean \pm s.e.

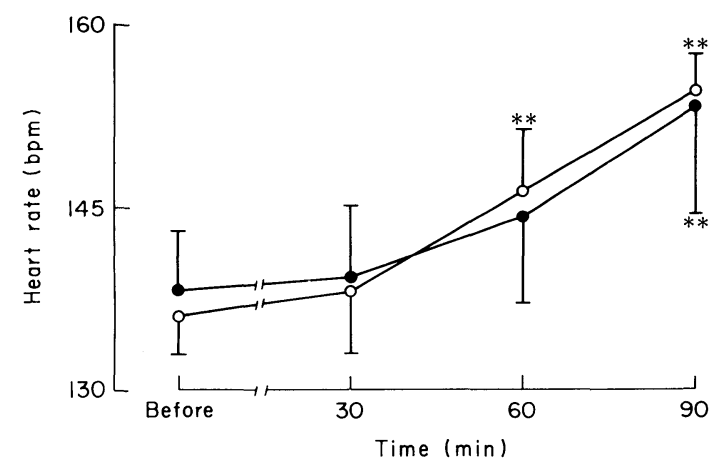

Fig. 2. Changes of heart rates after oral denopamine in group 1 ( $\mathrm{O}$ ) and group 2 (•). ${ }^{* *} p<0.01$ compared with baseline values. Heart rates began to increase at $60 \mathrm{~min}$ after denopamine administration. In group 1 it increased from $136 \pm 3$ to $154 \pm 3 \mathrm{bpm}$, and in group 2 from $138 \pm 5$ to $153 \pm 9 \mathrm{bpm}$. 
$24.2 \pm 1.8 \mathrm{~mm}$ ). LVDs of both groups were decreased gradually during $90 \mathrm{~min}$, in group 1 from $15.5 \pm 0.9$ to $12.7 \pm 1.2 \mathrm{~mm}$, and in group $2,15.5 \pm 1.3$ to $13.3 \pm 1.4 \mathrm{~mm}$, respectively. With these changes in dimensions, LVSF increased significantly in both groups; in group 1 from $0.43 \pm 0.02$ to $0.50 \pm 0.03$, and in group 2 from $0.40 \pm$ 0.02 to $0.47 \pm 0.02$, respectively (Fig. 3 ).

\section{Changes of peak velocities}

Both aortic and pulmonary peak velocities of group 1 and 2 increased from $60 \mathrm{~min}$ after denopamine, and achieved peak level at $90 \mathrm{~min}$. Aortic peak velocities accelerated from $1.12 \pm 0.08$ to $1.36 \pm 0.08 \mathrm{~m} / \mathrm{sec}$ in group 1 , and from $1.11 \pm 0.07$ to $1.29 \pm 0.1 \mathrm{~m} / \mathrm{sec}$ in group 2 . Pulmonary peak velocities rose from $1.98 \pm 0.13$ to $2.52 \pm 0.17 \mathrm{~m} / \mathrm{sec}$ in group 1 , and from $1.85 \pm 0.11$ to $2.23 \pm 0.14 \mathrm{~m} / \mathrm{sec}$ in group 2, respectively. Despite these changes of aortic and plumonary peak velocities, the velocity ratio of pulmonary to aortic flow remained unchanged (Fig. $4 a)$.

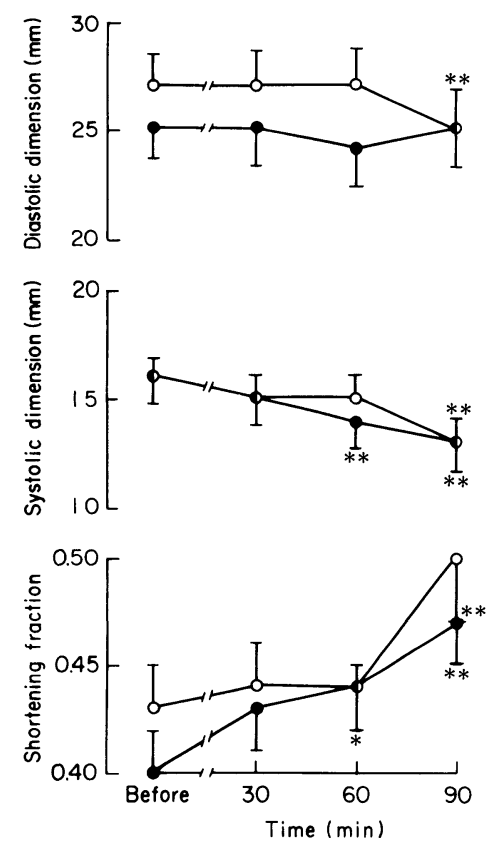

Fig. 3. Changes of left ventricular dimensions and shortening fraction after oral denopamine in group $1(0)$ and group $2(\bullet) .{ }^{*} p<0.05,{ }^{* *} p<0.01$ compared with baseline values. LVDd tended to decrease at $90 \mathrm{~min}$ in group 1 (from $27.1 \pm 1.5$ to $25.2 \pm 1.7 \mathrm{~mm}$ ). LVDs of both groups were deceased during 90 min, in group 1 from $15.5 \pm 0.9$ to $12.7 \pm 1.2 \mathrm{~mm}$, and in group 2 from $15.5 \pm 1.3$ to $13.3 \pm 1.4 \mathrm{~mm}$, respectively. LVSF increased in both groups as follows; in group 1 from $0.43 \pm 0.02$ to $0.50 \pm 0.03$, and in group 2 from $0.40 \pm 0.02$ to $0.47 \pm 0.02$. 

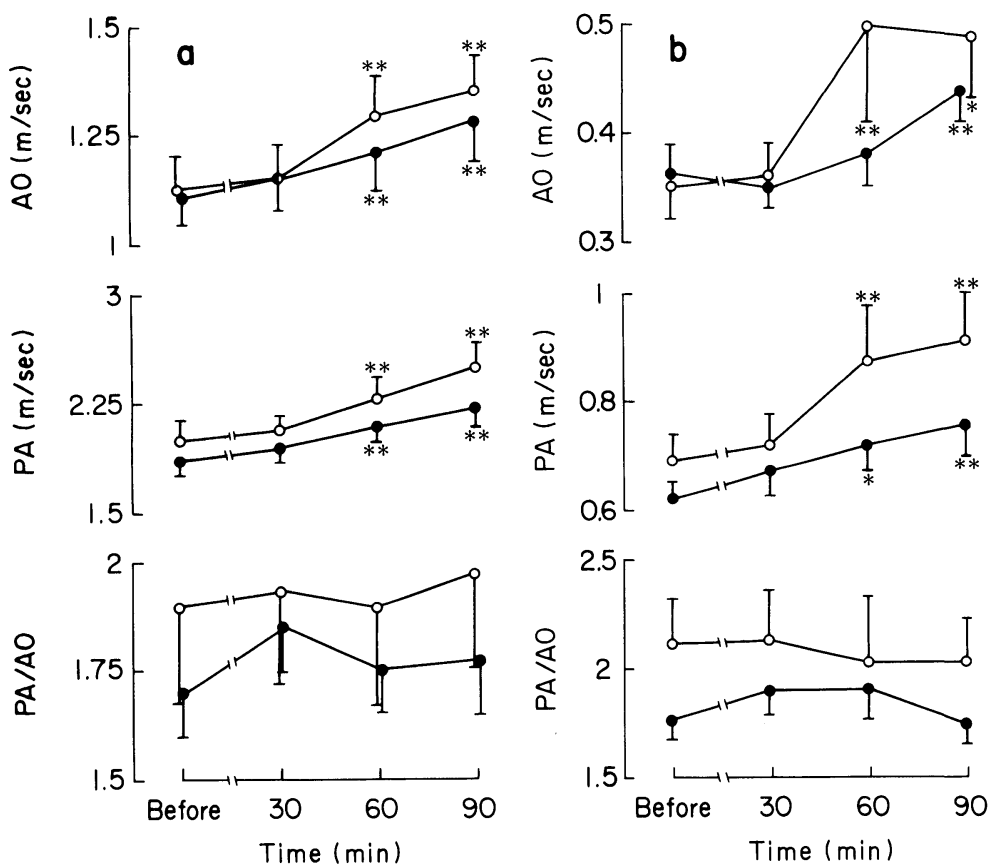

Fig. 4. Changes of peak (4a) and mean (4b) velocity in group $1(\mathrm{O})$ and group 2 (•). ${ }^{*} p<0.05,{ }^{* *} p<0.01$ compared with baseline values. AO; aorta, PA; pulmonary artery. Both aortic and pulmonary peak and mean velocities of group 1 and 2 increased significantly. Aortic peak velocities accelerated from $1.12 \pm 0.08$ to $1.36 \pm 0.08 \mathrm{~m} / \mathrm{sec}$ in group 1 , and from $1.11 \pm 0.07$ to $1.29 \pm 0.1 \mathrm{~m} /$ sec in group 2. Pulmonary peak velocities rose from $1.98 \pm 0.13$ to $2.52 \pm 0.17$ $\mathrm{m} / \mathrm{sec}$ in group 1 , and from $1.85 \pm 0.11$ to $2.23 \pm 0.14 \mathrm{~m} / \mathrm{sec}$ in group 2 . Aortic mean velocities increased from $0.35 \pm 0.03$ to $0.49 \pm 0.06 \mathrm{~m} / \mathrm{sec}$ in group 1 , and pulmonary mean velocities from $0.69 \pm 0.05$ to $0.92 \pm 0.08 \mathrm{~m} / \mathrm{sec}$. Aortic mean velocities went up from $0.36 \pm 0.03$ to $0.44 \pm 0.03 \mathrm{~m} / \mathrm{sec}$, and pulmonary mean velocities from $0.62 \pm 0.03$ to $0.76 \pm 0.06 \mathrm{~m} / \mathrm{sec}$ in group 2 . The velocity ratios of peak and mean pulmonary to aortic flow remained unchanged.

\section{Changes of mean velocities}

Changes of mean velocities, and the velocity ratio of pulmonary to aortic flow were basically the same as those of the peak. In group 1, aortic mean velocities increased from $0.35 \pm 0.03$ to $0.49 \pm 0.06 \mathrm{~m} / \mathrm{sec}$, and pulmonary mean velocities from $0.69 \pm 0.05$ to $0.92 \pm 0.08 \mathrm{~m} / \mathrm{sec}$. Aortic mean velocities went up from $0.36 \pm$ 0.03 to $0.44 \pm 0.03 \mathrm{~m} / \mathrm{sec}$, and pulmonary mean velocities from $0.62 \pm 0.03$ to $0.76 \pm$ $0.06 \mathrm{~m} / \mathrm{sec}$ in group 2. There was no significant alteration in the mean velocity ratio of pulmonary to aortic flow, as was the peak velocity ratio (Fig. $4 \mathrm{~b}$ ). 
Percent changes of each index and the serum concentration of denopamine at 90 min in 2 groups

There is considerable disparity of the serum concentration at $90 \mathrm{~min}$ in both groups, its distribution in group 1 was 7.2 to $137.6(47.5 \pm 13.6)$, and $5.2 \pm 82.7$ $(37.3 \pm 10.1) \mathrm{ng} / \mathrm{ml}$ in group 2 (Fig. 5). Although average percentage changes of all indices except LVSF, and the average serum concentration of denopamine in group 1 were larger than those in group 2, the difference between two groups was not statistically significant (Table 2 ). The serum concentration of denopamine exponentially correlated to percentage changes of HR, LVDs, peak aortic velocity, and mean aortic and pulmonary velocity (Table 3 ).

\section{Discussion}

It is still controversial whether inotropic agent is necessary for the treatment

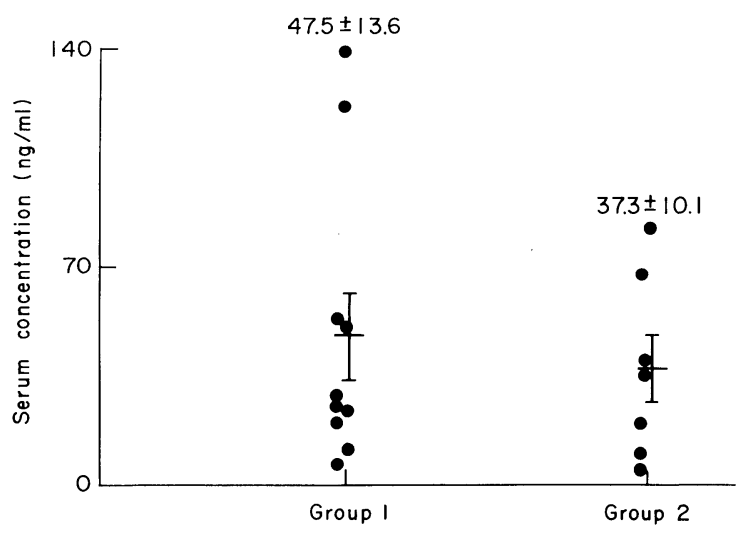

Fig. 5. Serum concentrations of denopamine at $90 \mathrm{~min}$ after oral administration. These distributed 7.2 to $137.6(47.5 \pm 13.6) \mathrm{ng} / \mathrm{ml}$ in group 1, and 5.2 to 82.7 $(37.3 \pm 10.1) \mathrm{ng} / \mathrm{ml}$ in group 2. There was no statistically significant difference between the two groups.

TABLE 2. Percentage changes of parameters at 90 min after oral denopamine

\begin{tabular}{cccccccccccc}
\hline & & & & & \multicolumn{3}{c}{ Peak velocity } & \multicolumn{3}{c}{ Mean velocity } \\
\cline { 6 - 10 } & & LVDd & LVDs & LVSF & PA & AO & PA/AO & PA & AO & PA/AO \\
\hline Group 1 & 113.5 & 92.7 & 80.7 & 117.4 & 127.6 & 123.9 & 105.7 & 133.2 & 140.7 & 97.7 \\
& $(2.2)$ & $(2.2)$ & $(4.6)$ & $(4.9)$ & $(3.6)$ & $(6.1)$ & $(5.8)$ & $(5.4)$ & $(11.0)$ & $(4.8)$ \\
Group 2 & 111.2 & 97.2 & 85.8 & 119.0 & 121.1 & 115.8 & 104.4 & 123.6 & 125.1 & 100.7 \\
& $(3.4)$ & $(2.8)$ & $(3.9)$ & $(7.0)$ & $(5.0)$ & $(4.0)$ & $(3.5)$ & $(6.8)$ & $(7.1)$ & $(6.6)$ \\
\hline
\end{tabular}

( ): S.E.

HR, heart rate; LVDd, left ventricular diastolic dimension; LVDs, left ventricular systolic dimension;

LVSF, left ventricular shortening fraction; PA, pulmonary artery; AO, aorta. 
TABLE 3. Exponential correlation coefficiences between the denopamine concentration and percentage changes of parameters

\begin{tabular}{lcc}
\hline & $\mathrm{r}$ & $p$ \\
\hline HR & 0.69 & $<0.01$ \\
LVDd & -0.36 & n.s. \\
LVDs & -0.58 & $<0.05$ \\
LVSF & 0.34 & n.s. \\
Peak AOV & 0.65 & $<0.05$ \\
Peak PAV & 0.48 & n.s. \\
Peak PAV/AOV & -0.31 & n.s. \\
Mean AOV & 0.59 & $<0.05$ \\
Mean PAV & 0.59 & $<0.05$ \\
Mean PAV/AOV & 0.23 & n.s. \\
\hline
\end{tabular}

$\mathrm{AOV}$, aortic velocity; PAV, pulmonary velocity.

of congestive heart failure complicated with large ventricular septal defect. Because in the case of large ventricular septal defect, the congested state might not be primarily due to cardiac dysfunction but may be secondary to volume and pressure overload on the heart and lung. However, as regards the low output state of patients suffering large ventricular septal defect, some studies have indicated the beneficial actions of catecholamines (Nakazawa et al. 1987).

According to adult human data, denopamine has not only a potent inotropic action but also a preload-reducing action, despite the weakness of its chronotropic action (Ikeo et al. 1986). However, there is a paucity of data on its effectiveness in infants suffering congestive heart failure, especially complicated with large left to right shunt disease. We demonstrated that intravenous denopamine has potent inotropic and chronotropic actions in newborn piglets (Tomita et al. 1992). Furthermore it was regarded as systemic vasodilator at high dose (Tomita et al. 1992). In human infants, Ishikawa et al. (1989) reported acute hemodynamic changes by intravenous denopamine, and symptomatic validity of oral denopamine, concluding that denopamine can be the first line drug for congestive heart failure in infant. However, precise hemodynamic alterations and bioavailability of oral denopamine in infants with left to right shunt disease and pulmonary hypertension are still obscure.

In large left to right shunt disease, pharmacological alteration of hemodynamics reflects the sum of cardiac and vascular action. On the other hand, there are several studies on the systemic and pulmonary vasodilator actions of denopamine. However, noninvasive evaluation of vascular action on left to right shunt disease, especially in the pulmonary circulation, is usually difficult. Furthermore, in our present study, denopamine began to work at 60 min or more after oral administration, and heart rates of flow velocities can change easily 
depending on the conditions of subjects, like crying, respiration, and movement. Thus, patients must be kept very quiet at least 60 min to confirm the changes of indices by noninvasive method. For these reasons, we measured simple indices in this study, focusing on alterations of the left ventricular pump function and the systemic and pulmonary blood flow, that is, heart rate, left of ventricular dimensions, flow velocities, and compared to the serum concentration of denopamine.

Many investigators have confirmed that cardiac output estimated by Doppler echocardiography well correlates to that measured by Fick or thermodilution method (Alverson et al. 1982; Valdes-Cruz et al. 1984). There are certainly some potential sources of error to assess the cardiac output using Doppler echocardiographies, such as the angle between the ultrasound beam and blood flow, and the measurement of the vessel diameter (DiSessa and Friedman 1984; Gardin et al. 1985). However, in patients without stenotic lesions in ventricular outflow tract, changes of flow velocity itself can correlate to changes of flow volume. Based on this assumption, we interpreted the peak velocity as the index of stroke volume, and the mean velocity as of cardiac output.

In our present study, denopamine clearly augmented left ventricular pump function, and increased both stroke and total systemic and pulmonary output. In addition, as reported in adults, denopamine seemed to have some preload-reducing action judging from the finding that LVDd tended to decrease slightly, despite the increase in pulmonary blood flow. Although peak and mean velocity ratios of pulmonary to systemic flow remained unchanged, peak and mean pulmonary velocities accelerated up to 149.0 and $161.6 \%$ in a patient, respectively. From our piglet (Tomita et al. 1992) and other adult animal (Nagao et al. 1984; Ikeo and Nagao 1985; Ikeo et al. 1985) and human (Ikeo et al. 1986) studies, denopamine clearly has a weak systemic vasodilatory action. In addition, adult animal (Miyahara et al. 1990) and human (Ido et al. 1991) studies demonstrated its pulmonary vasodilatory action in the condition of increased pulmonary vascular resistance. Therefore, these increases in velocities may have been the result of cardiac and vascular actions of denopamine, and can be variable depending on the pulmonary vascular resistance of the patient. Although we could not clarify how diverse the changes of blood flow may be relating to the pulmonary vascular resistance in this study, we should be aware that an enormous acceleration of pulmonary blood flow might contribute to the aggravation of pulmonary congestion. Several investigations published so far have indicated that denopamine has a well-separated chronotropic and inotropic action (Ikeo and Nagao 1985; Nunoki et al. 1985; Ikeo et al. 1985, 1986). However, changes of left ventricular dimensions and flow velocities always accompanied an increase in heart rate. Furthermore, percentage increases of heart rate positively correlated to the serum concentration of denopamine. Therefore, the chronotropic action of denopamine is not insignificant in the doses of this study.

Although the optimal dose of oral denopamine for children is still controver- 
sial, a few studies have recommended to prescribe $1-2 \mathrm{mg} / \mathrm{kg} /$ day divided in three times (Ishikawa et al. 1989; Ishikawa 1993). Thus in this study, we evaluated acute hemodynamic effects of a single oral dose of either 0.5 or $1 \mathrm{mg} / \mathrm{kg}$. Effective serum concentrations of denopamine published so far are over $20 \mathrm{ng} / \mathrm{ml}$ in adults (Kino et al. 1983; Kawai et al. 1985), which were attained at 60-120 min after oral administration. In our present study, in three patients this level could not be attained at $90 \mathrm{~min}$, whereas in other two patients, serum concentrations of denopamine rose over $100 \mathrm{ng} / \mathrm{ml}$. This wide variation suggests a variability of intestinal absorption in infants, and further investigation should be carried out on the doses of oral denopamine. Furthermore, since percentage changes of most indices correlate to the serum concentration of denopamine, we should check the serum concentration to find its optimal oral doses in infants.

In conclusion, denopamine can be a choice in medical treatment of congestive heart failure complicated with ventricular septal defect and pulmonary hypertension, because it augments the left ventricular pump function and consequently enhances the systemic output. However, we should be careful for denopamine not to produce an excessive increase in heart rate and aggravation of pulmonary congestion.

\section{References}

1) Alverson, D.C., Berman, W., Jr., Eldrige, M.W., Yabek, S.M. \& Dillon, T. (1982) Noninvasive pulsed Doppler determination of cardiac output in neonates and children. J. Pediatr., 101, 46-50.

2) DiSessa, T.G. \& Friedman, W.F. (1984) Echocardiographic evaluation of cardiac performance. In: Pediatric Cardiac Imaging, edited by W.F. Friedman \& C.B. Higgins, Saunders, Philadelphia, pp. 219-231.

3) Gardin, J.M., Tobis, J.M., Dabestani, A., Smith, C., Elkayam, U., Castleman, E., White, D., Allfie, A. \& Henry, W.L. (1985) Superiority of two-dimensional measurement of aortic vessel diameter in Doppler echocardiographic estimates of left ventricular stroke volume. J. Am. Coll. Cardiol., 6, 66-74.

4) Ido, A., Tsuji, T., Shimizu, T., Fukuzawa, J., Fujiuchi, S., Fujita, Y., Ohki, Y., Sasaki, N., Sakai, E. \& Onodera, S. (1991) Effects of denopamine on hemodynamics and blood gases in secondary pulmonary hypertension. Nippon Kyobu Geka Gakkai Zasshi, 29, 1553-1559. (in Japanese with English abstract)

5) Ikeo, T. \& Nagao, T. (1985) Effects of denopamine (TA-064), a new positive inotropic agent, on myocardial oxygen consumption and left ventricular dimension in anesthetized dogs. Jpn. J. Pharmacol., 39, 179-189.

6) Ikeo, T., Nagao, T., Suzuki, T., Yabana, H. \& Nakajima, H. (1985) Cardiovascular effects and plasma levels of denopamine (TA-064), a new positive inotropic agent, in chronically instrumented dogs. Jpn. J. Pharmacol., 39, 191-199.

7) Ikeo, T., Nagao, T., Murata, S., Yabana, H., Sato, M. \& Nakajima, H. (1986) Cardiovascular effects of the new positive inotropic agent denopamine with special reference to species difference and the effect on failing heart. Arzneim.-Forsch., 36, 1063-1068.

8) Ishikawa, S. (1993) New cardiotonic agents. Shouninaika, 25, 414-421. (in Japanese)

9) Ishikawa, S., Sunagawa, H. \& Honda, S. (1989) Treatment of the congestive heart 
failure in the young with congenital heart disease by denopamine, A new oral $\beta 1$-adrenoceptor agent. Circulation, 80, Suppl. 2, 489.

10) Kawai, N., Okada, M., Koide, M., Tsuzuki, M., Tohata, I., Tanaka, M., Hirayama, H., Tsuzuki, M., Itoh, A., Tanahashi, Y. \& Inagaki, H. (1985) Acute and chronic effects of a new oral cardiotonic agent, denopamine, in patients with congestive heart failure. Yakuri to Chiryoh, 13, 2885-2895. (in Japanese)

11) Kino, M., Hirota, Y., Yamamoto, S., Sawada, K., Moriguchi, M., Kotaka, M., Kubo, S. \& Kawamura, K. (1983) Cardiovascular effect of a newly synthesized cardiotonic agent (TA-064) on normal and disease heart. Am. J. Cardiol., 51, 802-810.

12) Kino, M., Hirota, Y., Saitoh, T., Nakayama, A., Hara, M., Sawada, K., Yamamoto, S., Suwa, M., Kubo, S. \& Kawamura, K. (1986) Cardiovascular effects of a new inotropic agent, denopamine (TA-064), with reference to it's effects on cardiac hemodynamics and metabolism. Jpn. Circ. J., 50, 644-651.

13) Miyahara, K., Kai, M., Kawahara, S. \& Nakamoto, H. (1990) The hemodynamic effects of denopamine on experimental pulmonary hypertension dogs. J. Jpn. Coll. Angiol., 30, 1309-1315. (in Japanese with English abstract)

14) Nagao, T., Ikeo, T., Murata, S., Sato, M. \& Nakajima, H. (1984) Cardiovascular effects of a new positive inotropic agent, (-)-(R)-1-(p-Hydroxyphenyl)-2-[(3, 4 Dimethoxyphenethyl) Amino]-Ethanol (TA-064) in the anesthetized dog and isolated guinea pig heart. Jpn. J. Pharmacol., 35, 415-423.

15) Nakazawa, M., Takahashi, Y., Aiba, S., Okuda, H., Ohta, H. \& Takao, A. (1987) Acute hemodynamic effects of dopamine, dobutamine, and isoproterenol in congested infants or young children with large ventricular septal defect. Jpn. Circ. J., 51, 10101015.

16) Nunoki, K., Goto, T., Satoh, K. \& Taira, N. (1985) Improvement by denopamine (TA-064) of pentobarbital-induced cardiac failure in the dog heart-lung preparation. Heart Vessel, 1, 216-219.

17) Tagawa, K., Ueki, T., Mizobe, M., Noda, K. \& Samejima, M. (1990) Determination of denopamine in human and dog plasma by high-performance liquid chromatography with electrochemical detection. J. Chromatogr., 529, 500-506.

18) Tomita, H., Coe, J.Y. \& Olley, P.M. (1992) Circulatory effects of denopamine in newborn piglets. Acta Paediatr. Jpn., 34, 393-397.

19) Valdes-Cruz, L.M., Horowitz, S., Mesel, E., Sahn, E.J., Fisher, D.C. \& Larson, D. (1984) A pulsed Doppler echocardiographic method for calculating pulmonary and systemic blood flow in atrial level shunts; Validation studies in animals and initial human experiences. Circulation, 69, 80-86. 